\title{
Influence of preoperative information support on anxiety, pain and satisfaction with postoperative analgesia in children and adolescents after thoracic surgery: A randomized double blind study
}

\author{
Lucyna Tomaszek ${ }^{\mathrm{a}}$, Grazyna Cepuch ${ }^{\mathrm{b}}$, Dariusz Fenikowski
}

\begin{abstract}
Aims/Background. The proportion of patients who experience anxiety prior to planned surgery, even a minimally invasive one, is estimated at 50-70\%. Thoracic surgery, causes significant preoperative anxiety, especially in children. The aim of this study was to determine the effect of an important component of psychological preparation for a surgery as information support on levels of anxiety, pain and satisfaction with postoperative analgesia.

Methods. The randomized double blind study including patients aged 9-18 years qualified for lateral thoracotomy or Ravitch procedure. The subjects were randomized to the control group $(n=56)$ provided with a routine preoperative information by a nurse, and the experimental group $(n=56)$ offered additional psychological consultation. Data were collected via the State-Trait Anxiety Inventory.

Results. In the experimental group, the level of state anxiety at $48 \mathrm{~h}$ post-surgery was significantly lower than prior to the procedure, but only in subjects with preoperative trait anxiety $<7 / 10$ sten. In the control group, the level of postoperative anxiety was significantly higher than prior to the surgery; this effect was observed irrespectively of preoperative trait anxiety level. Lack of preoperative psychological consultation $(\beta=-0.23)$, trait anxiety $\geq 7$ sten $(\beta=0.25)$, and higher level of preoperative state anxiety $(\beta=0.65)$ were independent predictors of greater state anxiety at $48 \mathrm{~h}$ post-surgery. Patients from the experimental group did not differ significantly from the controls in terms of their median pain scores and satisfaction with postoperative analgesia. Greater state anxiety was associated with $22 \%$ lesser likelihood of complete satisfaction with the analgesia.

Conclusion. Information support from a psychologist offered prior to a thoracic surgery decrease the level of postoperative state anxiety solely in children with lower levels of trait anxiety. Higher level of postoperative state anxiety negatively affect patients' satisfaction with post-surgical analgesia.

Trial Registration: ClinicalTrials.gov; Influence of Preoperative Support on Anxiety, Pain and Satisfaction With Postoperative Analgesia; NCT03488459, https://clinicaltrials.gov/ct2/show/record/NCT03488459?cntry=PL\&city=RabkaZdr\%C3\%B3j\&rank=1
\end{abstract}

Key words: anxiety, preoperative education, psychologist, thoracotomy, Ravitch procedure, postoperative pain

Received: April 8, 2018; Accepted with revision: September 21, 2018; Available online: October 5, 2018 https://doi.org/10.5507/bp.2018.060

${ }^{a}$ Department of Thoracic Surgery, Institute for Tuberculosis and Lung Diseases, Pediatric Division, Rabka-Zdroj, Poland ${ }^{b}$ Collegium Medicum, Faculty of Health Sciences, Jagiellonian University, Krakow, Poland Corresponding author: Lucyna Tomaszek, Itomaszek@igrabka.edu.pl

\section{INTRODUCTION}

Thoracic surgery, as any other surgical procedure, constitutes a considerable mental load for a pediatric patient, and generates significant preoperative anxiety. The proportion of patients who experience anxiety prior to a planned surgery, even a minimally invasive one, is estimated at $50-70 \%$ (ref. ${ }^{1,2}$ ). The sources of anxiety include the stay in an unfamiliar hospital environment, the sense of lost control, fear of unknown or pain, among others.

High level of preoperative anxiety is postulated to contribute to its greater postoperative intensity ${ }^{3-6}$, which may in turn be reflected by less effectiveness of pain control $^{4}$, adverse changes in child's behavior after hospital discharge (e.g. sleep and eating disorders) (ref. ${ }^{4,7}$ ). Nevertheless, published evidence regarding the link between anxiety and postoperative pain is conflicting. While according to some authors, children and adolescents pre- senting with higher levels of preoperative anxiety may experience stronger pain after the procedure ${ }^{4,8}$, others have found no such relationship ${ }^{9,10}$.

Current guidelines on the management of postoperative pain are based on two key recommendations: individualized approach and use of multimodal analge$\mathrm{sia}^{11,12}$; integral component of the latter is preoperative education $^{13}$. Educational interventions can range from single episodes of face-to-face instruction or provision of written information to more intensive multicomponent preoperative interventions including a computer-based intervention, a photo file, an operating area tour or teaching coping skills ${ }^{10,14-16}$. Such forms of support can be offered by all individuals involved in the therapeutic process, in particular by nurses ${ }^{17}$ and psychologists ${ }^{18}$.

Information support should be considered both an important component of psychological preparation for a surgery, and an important source of support for child's 
personal resources. Unfortunately, routine information about the extent of perioperative care is not sufficient for adequate control of anxiety, as inter alia shown by Li and Chung ${ }^{14}$. Abundance of high-quality information support adjusted for individual needs contributes considerably to a decrease in the anxiety associated with planned surgery and to better cooperation between the patient and an interdisciplinary medical team.

The aim of this study was to analyze a relationship between information support provided by an interdisciplinary team and the levels of anxiety, pain and satisfaction with postoperative analgesia in children and adolescents subjected to thoracic surgeries.

\section{METHODS}

\section{Trial design and participants}

The double-blind randomized study, conducted at the Department of Thoracic Surgery in Rabka Zdroj, between March 2012 and December 2014, included consecutive pediatric patients qualified for surgical thoracic procedures.

Inclusion criteria of the study were: written informed consent from patient's legal guardians, age between 9 and 18 years, qualification for thoracic surgery (lateral thoracotomy or Ravitch procedure), and the American Society of Anesthesiologists (ASA) score 1 or 2.

Presence of a mental disorder, anticancer treatment, preoperative pain, problems with verbal communication and lack of postoperative drainage of the chest were considered exclusion criteria of the study.

No important changes were made to the methods after trial began.

\section{Randomization}

The day before surgery subjects were consecutively enrolled and randomized to experimental or control group. The randomized sequence was determined at the beginning of the study and generated by a random number generator (simple randomization). The study was doubleblind: neither the patients and their legal guardians nor nurses from the intensive postoperative care unit were aware of the randomization outcome and the aim of this study.

Patients in the control group and their legal guardians obtained routine information about preoperative, intraoperative and postoperative care, including information about pain scoring system and instruction how to use it, rules of planned analgesia, monitoring of vital parameters and training in respiratory gymnastics. All this information was provided by an appropriately trained anesthesiology nurse (who assigned participants to interventions). Before obtaining the information, each patient completed an anxiety severity survey.

Patients in the experimental group received additional information support from a psychologist. Session with the psychologist lasted approximately $45 \mathrm{~min}$. The protocol of the session included initial assessment of patient's psychological status, obtaining information about his/her previous pain experiences, his/her personal attitude to pain and disease as the cause of surgery, familiarizing the patient with the relationships between psychological factors and pain (suggestion to focus on positive consequences of the surgery), discussion on available and tailored pain coping strategies including those used previously by the patient, emphasizing important role of active involvement in therapeutic process (e.g. reliable pain assessment, treatment compliance). The aim of all these activities was to convince patients that postoperative pain can be controlled, resulting in improvement of overall functioning.

\section{Intraoperative and postoperative pain control}

For the thoracic surgical procedure, patients received general anesthesia, alone or combined with thoracic epidural anesthesia. All patients were premedicated with midazolam $(0.2-0.5 \mathrm{mg} / \mathrm{kg})$, and then, fentanyl $(1-5 \mu \mathrm{g} /$ $\mathrm{kg})$, propofol (3-5 mg/kg), pancuronium $(0.1 \mathrm{mg} / \mathrm{kg})$ or rocuronium $(1 \mathrm{mg} / \mathrm{kg}$ in children $<10$ years old $)$ and sevoflurane were used to introduce and maintain the anesthesia. Thoracic epidural catheters were placed following induction of anesthesia and endotracheal intubation.

In children operated on under general anesthesia, intraoperative analgesia was achieved with fentanyl injections (1-5 $\mu \mathrm{g} / \mathrm{kg}$ ) repeated every 20-30 min. In children subjected to combined general and epidural anesthesia, intraoperative analgesia was induced by a single dose (max. $2 \mathrm{mg} / \mathrm{kg}$ ) of $0.5 \%$ bupivacaine, followed by an infusion of $0.125-0.25 \%$ bupivacaine with fentanyl $(5 \mu \mathrm{g} / \mathrm{mL})$ 90 min later.

Patients in both groups were extubated at the conclusion of the procedure and transferred to the intensive postoperative care unit. Postoperative analgesia was achieved with a continuous intravenous infusion of morphine (20$50 \mu \mathrm{g} / \mathrm{kg} / \mathrm{h}$ ) or continuous epidural infusion of 0.125 $0.25 \%$ bupivacaine with fentanyl $(5 \mu \mathrm{g} / \mathrm{mL})$. Irrespective of the type of postoperative analgesia, non-opioid painkillers, such as paracetamol (15 mg/kg intravenously), metamizole (20 mg/kg intravenously), non-steroidal antiinflammatory drugs (NSAIDs): ketoprofen ( $1 \mathrm{mg} / \mathrm{kg}$ intravenously) and ibuprofen (10 $\mathrm{mg} / \mathrm{kg}$ orally or rectally) were given for interim control of pain.

\section{Outcome measures}

Analyzed variables included level of anxiety (primary outcome), severity of pain, and satisfaction with postoperative analgesia (secondary outcomes).

Anxiety was determined using a Polish version of the self-inventory, either for children between 9 and 14 years of age, i.e. State-Trait Anxiety Inventory for Children (STAI-C; range: $20-60$ pts) (ref. ${ }^{19}$ ) or for adolescents, i.e. State-Trait Anxiety Inventory (STAI; range: 20-80 pts) $\left(\right.$ ref. $\left.^{20}\right)$. The instrument consisted of two separate 20-item scales measuring state and trait anxiety. In this study, the levels of anxiety were determined twice: one day prior to surgery (both trait and state anxiety) and $48 \mathrm{~h}$ after the procedure (only state anxiety). The results were expressed as sten scores, from 1-10; sten score of 5 and 6 was interpreted as a moderate level of anxiety; sten score of 7 and more was interpreted as a high level of anxiety.

The severity of pain was assessed 1, 2, 4, 11, 24 and 48 
$h$ after the end of anesthesia. Pain severity was measured with the Numerical Rating Scale (NRS; range 0-10 points) at rest, during deep breathing and coughing ${ }^{21,22}$. The therapeutic goal of pain control was to reduce the severity of pain during coughing to no more than 2 points. Average pain scores for each patient at rest, during deep breathing and coughing were calculated.

Satisfaction with postoperative analgesia (after $48 \mathrm{~h}$ of observation) was rated on a 4-item scale; analgesia was rated as insufficient, poor, good or very good.

\section{Statistical analysis}

The data were processed using Statistica 12 package (StatSoft ${ }^{\circledR}$, Poland). The results are shown as means (SD) or medians (interquartile range) as appropriate. Normal distribution of quantitative variables was determined by the Shapiro-Wilk W-test. The Student t, Chi squared, Mann Whitney, Wilcoxon probability tests were used to analyse the data. Power and direction of associations within pairs of quantitative variables were determined on the basis of Spearman's rank correlation coefficients (R). Effects of multiple explanatory variables on the level postoperative state anxiety were tested in a multiple regression model. Effects of the level of postoperative state anxiety on the satisfaction with postoperative analgesia (expressed as a dichotomous variable: very good and good) were tested in a logistic regression model (B, regression coefficient; $\mathrm{CI}$, confidence interval; OR, odds ratio). Threshold of statistical significance for all tests was set at $P=0.05$.

\section{Sample Size Estimation}

The minimal sample size was estimated based on the results of the preliminary study using $\mathrm{t}$ - test for dependent samples. Power calculations were based on the assumption that the study would have $80 \%$ power (alpha $=0.05$ ) to detect differences between preoperative and postoperative state anxiety scores in either the experimental $(n=10)$ or control group $(n=10)$. Taking into account mean values and standard deviations for preoperative and postoperative state anxiety levels and correlation between these two parameters, minimal sample size for the experimental and control group was estimated at $36(6.05 \pm 1.86$ vs. $5.35 \pm 1.95 ; \mathrm{R}=0.71)$ and 55 patients $(5.12 \pm 2.01$ vs. $5.78 \pm 1.74 ; \mathrm{R}=0.59)$, respectively.

\section{Ethics}

The study was carried out according to the ethical principles of the Helsinki Declaration. Participation in the study was voluntary and written informed consent to participate in the study was sought from legal guardians of all patients. The protocol of the study was approved by the Local Bioethics Committee at the National Institute of Tuberculosis and Lung Diseases in Warsaw (decision no. KB-64/2012). This study was registered in the ClinicalTrials.gov (Identifier: NCT03488459).

\section{RESULTS}

\section{Participants}

The analysis included data of 56 patients in the experimental group and 56 controls; 4 (3.4\%) patients were excluded owing to a change in the protocol of postoperative analgesia, which was considered a potential confounder of the study findings (Fig. 1). The study groups did not differ significantly in terms of age, sex, body weight, body height, ASA scores, duration of anesthesia, duration of surgery, levels of trait anxiety and preoperative state anxiety, type of surgical procedure and postoperative analgesia (Table 1). Moreover, no significant intergroup differences in mean cumulative doses of bupivacaine, fentanyl and morphine were found. There was no difference in the number of doses of non-opioid drugs used between groups (Table 2).

The majority of patients $(n=84)$ were subjected to the Ravitch procedure due to deformation of anterior thoracic wall, namely funnel chest $(n=62)$, pigeon chest $(n=17)$ or combination thereof $(n=5)$. A single drain was placed in a retrosternal space in the vast majority of these subjects $(n=83,98.8 \%)$. The remaining patients $(n=28)$ were subjected to thoracotomy due to presence of mediastinal and pulmonary cysts $(n=9)$, pleural empyema $(n=4)$, emphysema $(n=6)$, bronchial atelectasis $(n=2)$, pulmonary tumors $(n=1)$ and other conditions $(n=6)$. In these subjects, one $(n=19,67.9 \%)$ or two drains $(n=9,32.1 \%)$ were placed in pleural cavity. Aside from the primary condition, 5 (4.5\%) children presented with concomitant bronchial asthma $(n=2)$, epilepsy $(n=2)$ and Marfan syndrome $(n=1)$.

\section{Anxiety}

Multiple linear regression analysis demonstrated that lack of preoperative psychological consultation, trait anxiety $\geq 7$ sten and higher level of preoperative state anxiety

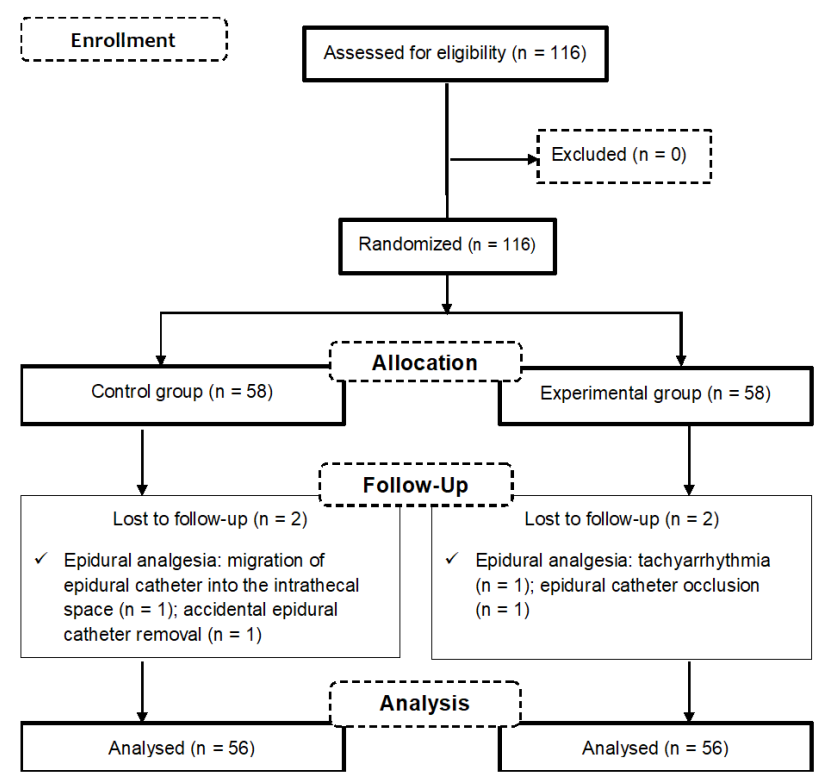

Fig. 1. CONSORT Flow Diagram of patients' enrollment. 
Table 1. Comparison of patients from the control and experimental group in terms of demographic and clinical characteristics.

\begin{tabular}{|c|c|c|c|c|c|}
\hline \multicolumn{2}{|l|}{ Parameter } & $\begin{array}{l}\text { Control group } \\
(\mathrm{n}=56)\end{array}$ & $\begin{array}{l}\text { Experimental group } \\
(\mathrm{n}=56)\end{array}$ & Test statistic & $P$ \\
\hline \multicolumn{2}{|l|}{ Age (years) } & $14.2 \pm 2.2$ & $14.3 \pm 2.2$ & $\mathrm{t}=-0.29$ & 0.765 \\
\hline \multicolumn{2}{|l|}{ Body height $(\mathrm{cm})$} & $167.3 \pm 11.9$ & $168.1 \pm 13.9$ & $\mathrm{t}=-0.32$ & 0.746 \\
\hline \multicolumn{2}{|l|}{ Body weight (kg) } & $53.8 \pm 11.9$ & $53.3 \pm 15.0$ & $\mathrm{t}=0.19$ & 0.846 \\
\hline \multicolumn{2}{|l|}{ Duration of anesthesia (min) } & $218 \pm 59$ & $211 \pm 59$ & $\mathrm{t}=0.63$ & 0.527 \\
\hline \multicolumn{2}{|l|}{ Duration of surgery (min) } & $170 \pm 59$ & $163 \pm 53$ & $t=0.64$ & 0.521 \\
\hline \multicolumn{2}{|c|}{ Preoperative state anxiety (range: $1-10$ sten) } & $6(4-6.5)$ & $6(5-7)$ & $Z=-1.84$ & 0.065 \\
\hline \multicolumn{2}{|l|}{ Trait anxiety (range: $1-10$ sten) } & $5(3.5-7)$ & $5(4-6)$ & $\mathrm{Z}=0.05$ & 0.958 \\
\hline \multicolumn{2}{|c|}{ Patients with high level of trait anxiety ( $\geq 7$ sten) } & $14(25 \%)$ & $12(21.4 \%)$ & $\chi^{2}=0.20$ & 0.654 \\
\hline \multirow[t]{2}{*}{ Sex } & Girls & $12(21.4 \%)$ & $16(29.6 \%)$ & $\chi^{2}=0.76$ & 0.382 \\
\hline & Boys & $44(78.6 \%)$ & $40(71.4 \%)$ & & \\
\hline \multirow[t]{2}{*}{ ASA } & 1 & $52(92.9 \%)$ & $50(89.3 \%)$ & $\chi^{2}=0.10$ & 0.742 \\
\hline & 2 & $4(7.1 \%)$ & $6(10.7 \%)$ & & \\
\hline \multirow[t]{2}{*}{ Type of surgery } & Thoracotomy & $14(25 \%)$ & $14(25 \%)$ & $\chi^{2}=0.00$ & 1.000 \\
\hline & Ravitch & $42(75 \%)$ & $42(75 \%)$ & & \\
\hline \multirow[t]{2}{*}{ Type of postoperative analgesia } & $\mathrm{B}+\mathrm{FNT}$ & $37(66.1 \%)$ & $35(62.5 \%)$ & $\chi^{2}=0.15$ & 0.693 \\
\hline & MF & $19(33.9 \%)$ & $21(37.5 \%)$ & & \\
\hline
\end{tabular}

Results presented as mean (standard deviation), medians (interquartile ranges) or numbers (percentages); ASA, American Society of Anesthesiologists; B+FNT, epidural bupivacaine and fentanyl; MF, intravenous morphine

Table 2. Comparison of patients from the control and experimental group in terms of drugs consumption by postoperative day.

\begin{tabular}{lccccc}
\hline Parameter & & $\begin{array}{c}\text { Control group } \\
(\mathrm{n}=56)\end{array}$ & $\begin{array}{c}\text { Experimental group } \\
(\mathrm{n}=56)\end{array}$ & Test statistic & $P$ \\
\hline Bupivacaine $(\mathrm{mg})$ & POD 1 & $292.5 \pm 128.1$ & $308.7 \pm 89.4$ & $\mathrm{t}=0.60$ & 0.545 \\
& POD 2 & $246.7 \pm 119.9$ & $271.2 \pm 99.3$ & $\mathrm{t}=0.92$ & 0.358 \\
Fentanyl $(\mu \mathrm{g})$ & POD 1 & $609.9 \pm 203.4$ & $637.7 \pm 184.2$ & $\mathrm{t}=0.59$ & 0.550 \\
& POD 2 & $537.6 \pm 190.3$ & $549.4 \pm 201.0$ & $\mathrm{t}=0.25$ & 0.799 \\
Morphine $(\mathrm{mg})$ & POD 1 & $40.6 \pm 13.4$ & $41.6 \pm 16.2$ & $\mathrm{t}=0.84$ & 0.842 \\
& POD 2 & $28.3 \pm 8.7$ & $35.4 \pm 15.4$ & $\mathrm{t}=0.07$ & 0.079 \\
Number doses of non-opioid drugs & POD 1 & $3(2-5)$ & $3(2-5)$ & $\mathrm{Z}=-0.08$ & 0.935 \\
& POD 2 & $4(2-6)$ & $3(2-5)$ & $\mathrm{Z}=0.81$ & 0.416 \\
\hline
\end{tabular}

Results presented as mean (standard deviation), median (interquartile ranges); POD, postoperative day

Table 3. Multivariate linear regression analyses predicting postoperative anxiety.

\begin{tabular}{lccc}
\hline Predictors & $\beta$ & $95 \% \mathrm{Cl}$ & $P$ \\
\hline Group (reference group = control) & -0.23 & -0.37 to -0.09 & $<0.001$ \\
Trait anxiety $\geq 7$ & 0.25 & 0.12 to 0.38 & $<0.001$ \\
Preoperative state anxiety & 0.65 & 0.51 to 0.78 & $<0.001$ \\
\hline
\end{tabular}

$\beta$, standardized regression coefficient; $\mathrm{Cl}$, confidence interval $\mathrm{R} 2=0.53 ; \mathrm{F}(3.108)=41.229 ; \mathrm{P}<0.01$

were independent predictors of greater state anxiety at 48 h post-surgery (Table 3 ).

The moderate level of preoperative state anxiety was diagnosed in 57/112 (50.9\%) and the high level of preoperative state anxiety were diagnosed in 36/112 (32.1\%) patients.

Whereas in patients in the experimental group the level of state anxiety at $48 \mathrm{~h}$ post-surgery was significantly lower than prior to the procedure $(\mathrm{Z}=3.357, P<0.001)$, the level of postoperative anxiety in the controls increased significantly compared to its preoperative level $(Z=2.146$, $P=0.031$ ) (Fig. 2).

In patients in the control group with preoperative trait anxiety $\geq 7$ sten, the level of postoperative state anxiety was significantly higher than prior to the procedure. In contrast, the level of postoperative state anxiety in pa- 


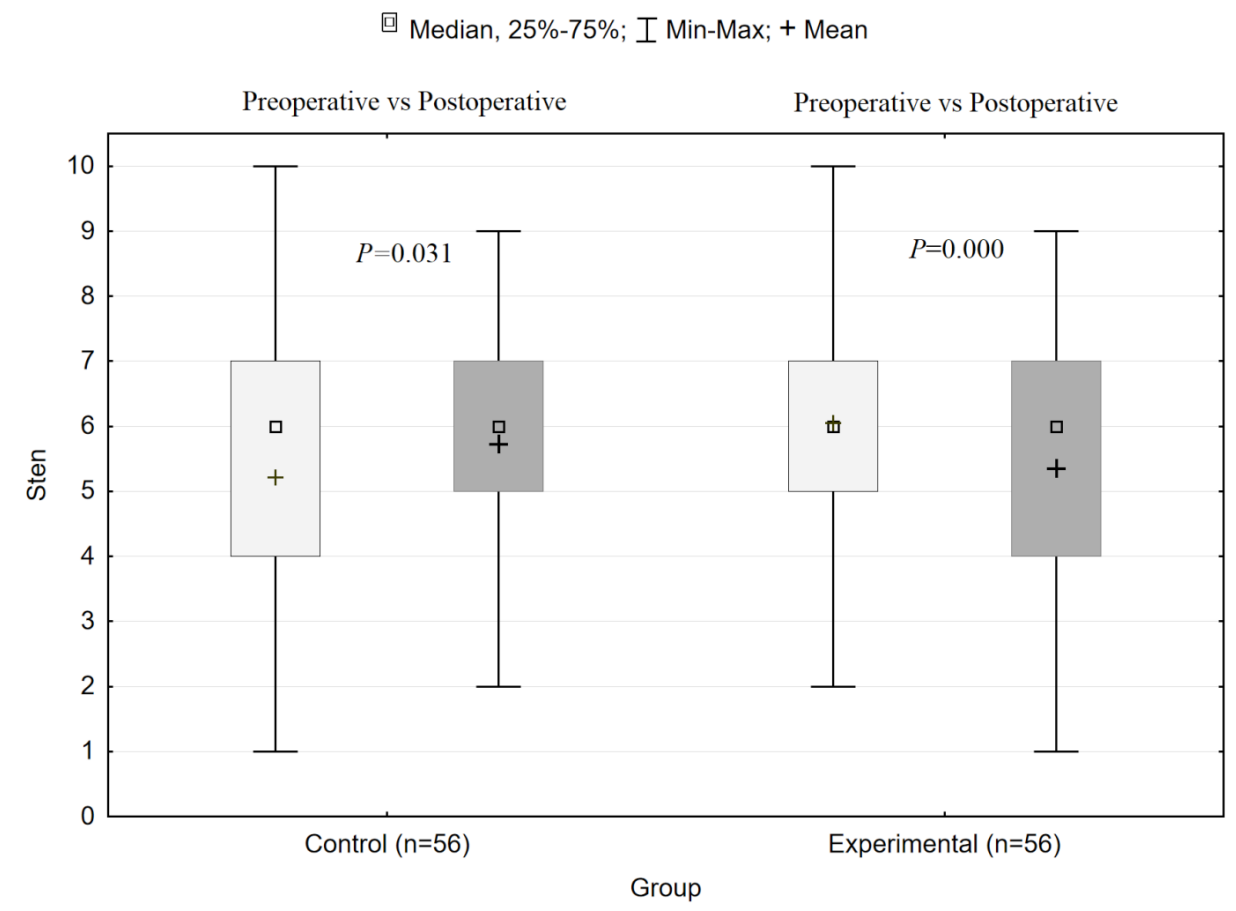

Fig. 2. Preoperative and postoperative state anxiety levels in patients from the experimental and control group (results presented as mean, median; the limits of the box show the interquartile range).

Table 4. Preoperative and postoperative state anxiety levels in patients with high trait anxiety ( $\geq 7$ sten) from the control and experimental group.

\begin{tabular}{lcccc}
\hline Group & Preoperative & Postoperative & Test statistic & $P$ \\
\hline Control $(\mathrm{n}=14)$ & $6(3-7)$ & $6(6-8)$ & $\mathrm{Z}=2.00$ & 0.045 \\
Experimental $(\mathrm{n}=12)$ & $7(6-8)$ & $7(7-7.5)$ & $\mathrm{Z}=0.41$ & 0.674 \\
\hline
\end{tabular}

Results presented as medians and interquartile ranges

tients in the experimental group with preoperative trait anxiety $\geq 7$ sten remained at a similar level than preoperatively (Table 4).

Analysis of correlation involving the results for all the study subjects, irrespective of the group, demonstrated statistically significant associations between preoperative and postoperative state anxiety $(\mathrm{R}=0.6, \mathrm{t}=8.26, P<0.001)$, preoperative state anxiety and trait anxiety $(\mathrm{R}=0.4, \mathrm{t}=4.92$, $P<0.001)$, postoperative state anxiety and trait anxiety $(\mathrm{R}=0.5, \mathrm{t}=6.96, P<0.001)$, perioperative state anxiety (i.e. pre- and postoperative state anxiety) and patient age $(\mathrm{R}=-$ $0.4, P<0.001)$.

\section{Postoperative Pain}

Patients in the experimental group did not differ significantly $(P>0.05)$ from the controls in terms of their median pain scores at rest (1 vs. 1), during deep breathing (2 vs. 2 ) and coughing (2 vs. 2 ).

\section{Satisfaction with postoperative analgesia}

Patients in the experimental group did not differ significantly from the controls in terms of their satisfaction with postoperative analgesia $(\chi 2=0.03, P=0.850)$. In pa- tients opinion, the quality of postoperative analgesia was either very good $(n=55,49.1 \%)$ or $\operatorname{good}(n=57,50.9 \%)$.

Logistic regression analysis demonstrated that high level postoperative state anxiety was significant predictor of less satisfaction with postoperative analgesia $(B:-0.24$, $P=0.028$ ). Greater state anxiety was associated with $22 \%$ less likelihood of complete satisfaction with the analgesia (OR: $0.78,95 \%$ CI: 0.63 to 0.97 ).

\section{DISCUSSION}

This study showed that in children whose preparation for surgery included psychological consultation, the level of postoperative state anxiety was significantly lower than preoperative level of this variable. Probably, extended information about pain coping strategies, adjusted for children's perception, strengthened their feeling of safety, and thus, contributed to less anxiety. In contrast, routine preoperative information provided by a nurse was presumably not adjusted for individual patients' demand, personal resources and current psychoemotional status, and therefore did not adequately alleviate their anxiety. 
Similar findings were previously reported by Brewer et al. ${ }^{23}$ These authors demonstrated that while the level of anxiety in children who were offered a standard preoperative consultation from a nurse increased post-surgery, the level of postoperative anxiety in patients who were additionally supported by a child life specialist was lower than at the baseline.

Our study demonstrated that patients with high levels of trait anxiety ( $\geq 7$ sten) did not benefit from preoperative support despite the involvement of a psychologist. The level of postoperative state anxiety in children in the control group was higher than prior to the procedure. Consequently, it cannot be excluded that even the maintenance of postoperative state anxiety at its preoperative level (the experimental group) should be considered a therapeutic success.

During psychological preparation for surgery, a correlation between perioperative state anxiety and patient age, also found in our study, should be considered as well. Previous studies demonstrated that younger children have higher levels of perioperative anxiety than older ones ${ }^{24}$, which can be explained by their less developed cognitive skills, greater dependence on others, lack of self-control, limited life experience and undeveloped understanding of health- and disease-related issues. These findings suggest that optimization of information support offered to patients from various age groups may constitute an invaluable asset improving their postoperative comfort and alleviating potential side effects of treatment.

Children and adolescents with higher levels of perioperative state anxiety may experience greater pain after the procedure; such conclusion was inter alia formulated by Chieng et al. ${ }^{5}$ on the basis of a systematic review of quantitative studies. This observation was also confirmed by Fortier et al. ${ }^{4}$ who found a positive correlation between the level of perioperative state anxiety and the severity of pain within initial $24 \mathrm{~h}$ after surgery on the larynx in children. Also in the study conducted by Lamontagne et al. ${ }^{25}$, the severity of pain at 2 and 4 days post-surgery correlated positively with the level of postoperative anxiety in adolescent patients operated on for scoliosis. However, these findings were not confirmed by all authors ${ }^{10,15,26}$. In this study too, there was no significant association between the level of perioperative state anxiety and the severity of postoperative pain.

Our presented findings are in opposition to the theory that children with higher levels of anxiety require more painkillers during postoperative period. Also the results of previous studies dealing with the problem in question are inconclusive. While Kain et al. ${ }^{27}$ found no significant anxiety-related differences in painkiller (codeine, acetaminophen) use during hospital stay, they demonstrated such differences after discharge. In turn, Logan and Rose $^{28}$ found an inverse correlation between preoperative state anxiety and patient-controlled analgesia demand, but found no significant anxiety-related difference in total amount of medication received. In our patients there were no significant differences in cumulative doses of either intravenous and epidural analgesics.
As mentioned, we found no link between the level of perioperative state anxiety, severity of postoperative pain and demand for analgesic agents. However, it should be emphasized that all children and adolescents participating in this study had been subjected to one of the most painful surgical procedures, i.e. thoracotomy with placement of intrathoracic drains. All received effective pain therapy with intravenous morphine or a mixture of epidural fentanyl and bupivacaine. Administered at a high dose, morphine and fentanyl exert sedative effects.

We found an association between the severity of postoperative anxiety and patient satisfaction with postoperative analgesia. In turn, presence of postoperative anxiety turned out to be a significant predictor of less satisfaction with analgesia. However, Rhodes et al. ${ }^{29}$ showed that patients who were given preoperative education - the intervention group -reported higher anxiety levels during the postoperative interval and higher satisfaction at discharge than patients from the control group. Royse et al. ${ }^{30}$ observed that only the nociceptive domain (pain or nausea) influenced satisfaction. Patient satisfaction with anesthesia care is usually reported as very high in different patient populations $^{29,30}$.

Study limitations: morphine and fentanyl exert sedative effects.

\section{Relevance to clinical practice}

These results advocate training for nurses to provide individually tailored information support to patients before thoracic surgery. Patients with elevated levels of trait anxiety should be identified prior to surgery and offered a dedicated educational program to prepare them for the surgical procedure adequately to their emotional status.

\section{CONCLUSION}

Information support from a psychologist offered prior to a thoracic surgery decrease the level of postoperative state anxiety solely in children with lower levels of trait anxiety. The severity of postoperative pain is not modulated by the level of perioperative anxiety. Higher level of postoperative state anxiety negatively affect patients' satisfaction with post-surgical analgesia.

Acknowledgments: The authors would like to express their gratitude to psychologists, Danuta Fąfara, MSc and Laura Rudawska-Guzik, MSc; and nurses Danuta Gawron, MSc and Halina Komotajtys, BSc.

This work was supported in part by Grants No. 10.5 from the National Tuberculosis and Lung Diseases Research Institute, Poland.

Author contributions: LT: study design; LT: data collection and analysis; LT, GC, DF: manuscript preparation.

Conflict of interest: None declared. 


\section{REFERENCES}

1. Justus R, Wyles D, Wilson J, Rode D, Walther V, Lim-Sulit N. Preparing children and families for surgery: Mount Sinai's multidisciplinary perspective. Pediatr Nurs 2006;32:35-43.

2. Kain ZN, Wang SM, Mayes LC, Krivutza DM, Teague BA. Sensory stimuli and anxiety in children undergoing surgery: a randomized controlled trial. Anesth Analg 2001;92:897-903.

3. Caumo W, Broenstrub JC, Fialho L, Petry SM, Brathwait O, Bandeira D, Loguercio A, Ferreira MB. Risk factors for postoperative anxiety in children. Acta Anaesthesiol Scand 2000;44:782-9.

4. Fortier MA, Del Rosario AM, Martin SR, Kain ZN. Perioperative anxiety in children. Paediatr Anaesth 2010;20:318-22.

5. Chieng YJ, Chan WC, Liam JL, Klainin-Yobas P, Wang W, Hi HG Exploring influencing factors of postoperative pain in schoolage children undergoing elective surgery. J Spec Pediatr Nurs 2013;18(3):243-52.

6. Chieng YJ, Chan WC, Klainin-Yobas P, He HG. Perioperative anxiety and postoperative pain in children and adolescents undergoing elective surgical procedures: a quantitative systematic review. J Adv Nurs 2014;70:243-55.

7. Power NM, Howard RF, Wade AM, Franck LS. Pain and behaviour changes in children following surgery. Arch Dis Child 2012;97:87984.

8. Crandall M, Lammers C, Senders C, Braun JV. Children's tonsillectomy experiences: influencing factors. J Child Health Care 2009;13:308-21.

9. Ericsson E, Wadsby M, Hultcrantz E. Pre-surgical child behavior ratings and pain management after two different techniques of tonsil surgery. Int J Pediatr Otorhinolaryngol 2006;70:1749-58.

10. Li HC, Lopez V, Lee TL. Psychoeducational preparation of children for surgery: the importance of parental involvement. Patient Educ Couns 2007;65:34-41.

11. Misiolek H, Cettler M, Woron J, Wordliczek J, Dobrogowski J, Mayzner-Zawadzka E. The 2014 guidelines for post-operative pain management. Anaesthesiol Intensive Ther 2014;46:221-44.

12. Glowacki D. Effective pain management and improvements in patients' outcomes and satisfaction. Crit Care Nurse 2015;35:33-43.

13. Chou R, Gordon DB, de Leon-Casasola OA, Rosenberg JM, Bickler $\mathrm{S}$, Brennan T, Carter T, Cassidy CL, Chittenden EH, Degenhardt E, Griffith S, Manworren R, McCarberg B, Montgomery R, Murphy J, Perkal MF, Suresh S, Sluka K, Strassels S, Thirlby R, Viscusi E, Walco GA, Warner L, Weisman SJ, Wu CL. Management of Postoperative Pain: A Clinical Practice Guideline From the American Pain Society, the American Society of Regional Anesthesia and Pain Medicine, and the American Society of Anesthesiologists' Committee on Regional Anesthesia, Executive Committee, and Administrative Council. J Pain 2016;17:131-57.

14. Li WH, Chung OK. Enhancing the efficacy of psychoeducational interventions for paediatric patients in a randomised controlled trial: methodological considerations. J Clin Nurs 2009;18:3013-21.

15. Fincher W, Shaw J, Ramelet AS. The effectiveness of a standardised preoperative preparation in reducing child and parent anxiety: a single-blind randomised controlled trial. J Clin Nurs 2012;21:946-55.

16. Fortier MA, Kain ZN. Treating perioperative anxiety and pain in children: a tailored and innovative approach. Paediatr Anaesth 2015;25:27-35.

17. Karimi R, Fadaiy Z, Nikbakht Nasrabadi A, Godarzi Z, Mehran A. Effectiveness of orientation tour on children's anxiety before elective surgeries. Jpn J Nurs Sci 2014;11:10-15.

18. Cuzzocrea F, Gugliandolo MC, Larcan R, Romeo C, Turiaco N, Dominici T. A psychological preoperative program: effects on anxiety and cooperative behaviors. Paediatr Anaesth 2013;23:139-43.

19. Jaworowska A. STAI-C - Inwentarz Stanu i Cechy Lęku dla Dzieci [STAI-C - State-Trait Inventory for Children]. Warsaw: Pracownia Testów Psychologicznych Polskiego Towarzystwa Psychologicznego; 2005.

20. Wrześniewski K, Sosnowski T, Jaworowska A, Fecenec D. Inwentarz Stanu i Cechy Lęku STAI. Polska adaptacja STAI. [State-Trait Inventory STAI. Polish adaptation of STAI.]. Warsaw: Pracownia Testów Psychologicznych Polskiego Towarzystwa Psychologicznego; 2011.

21. Manworren RC, Stinson J. Pediatric pain measurement, assessment, and evaluation. Semin Pediatr Neurol 2016;23:189-200.

22. Tomaszek L, Tomalak W, Gajdosz R, Buchwald J. Intermittent thoracic epidural administration of bupivacaine-morphine versus intravenous infusion of morphine after thoracic surgery in children and adolescents. Anest Ratow 2015;9:260-68.

23. Brewer S, Gleditsch SL, Syblik D, Tietjens ME, Vacik HW. Pediatric anxiety: child life intervention in day surgery. J Pediatr Nurs 2006;21:1322.

24. Perry JN, Hooper VD, Masiongale J. Reduction of preoperative anxiety in pediatric surgery patients using age-appropriate teaching interventions. J Perianesth Nurs 2012;27:69-81.

25. Lamontagne LL, Hepworth JT, Salisbury MH. Anxiety and postoperative pain in children who undergo major orthopedic surgery. Appl Nurs Res 2001;14:119-24.

26. Ferland CE, Saran N, Valois T, Bote S, Chorney JM, Stone LS, Ouellet JA. Preoperative distress factors predicting postoperative pain in adolescents undergoing surgery: a preliminary study. J Pediatr Health Care 2017;31:5-15.

27. Kain ZN, Mayes LC, Caldwell-Andrews AA, Karas DE, McClain BC. Preoperative anxiety, postoperative pain, and behavioral recovery in young children undergoing surgery. Pediatrics 2006;118:651-8.

28. Logan DE, Rose JB. Gender differences in post-operative pain and patient controlled analgesia use among adolescent surgical patients. Pain 2004;109:481-7.

29. Rhodes L, Nash C, Moisan A, Scott DC, Barkoh K, Warner WC Jr, Sawyer JR, Kelly DM. Does preoperative orientation and education alleviate anxiety in posterior spinal fusion patients? A prospective, randomized study. J Pediatr Orthop 2015;35:276-9.

30. Royse CF, Chung F, Newman S, Stygall J, Wilkinson DJ. Predictors of patient satisfaction with anaesthesia and surgery care: a cohort study using the Postoperative Quality of Recovery Scale. Eur J Anaesthesiol 2013:30:106-10. 